\title{
TINJAUAN RAK PENYIMPANAN DOKUMEN REKAM MEDIS TERHADAP EROGONOMI PETUGAS FILLING DI PUSKESMAS SOOKO KABUPATEN PONOROGO
}

\author{
Muklis Putri Ramadhani \\ (mukhlisputri60@gmail.com)
}

(Prodi D-III Rekam Medis dan Informasi Kesehatan STIKES Buana Husada Ponorogo)

\begin{abstract}
ABSTRAK
The medical record document storage rack is the main equipment in the filling room. Ergonomics is the study of human relations with work facilities, the worker's environment and daily life that surrounds it so that there is an alignment of work arrangements with humans to achieve a goal well. The purpose of this study was to determine the storage rack of medical record documents on the ergonomics of filling officers at the Sooko Health Center in Ponorogo Regency. This type of research is descriptive qualitative, using observation and interviews. The population of this study was filling officers totaling 3 people and medical record document storage racks. The sampling technique is total sampling. Data were analyzed descriptively. The results of research at the Sooko Health Center in Ponorogo Regency that the medical record document storage rack is not in accordance with the anthropometry of the filling officer. This is because the storage rack is high. Suggestions from researchers is to add tools such as stairs or other safe tools to retrieve and return medical record documents.
\end{abstract}

Keywords : Storage Rack, Ergonomics

\section{PENDAHULUAN}

Peraturan Menteri Kesehatan Republik Indonesia Nomor 75 Tahun 2014 Tentang Pusat Kesehatan Masyarakat Pusat Kesehatan Masyarakat yang selanjutnya disebut Puskesmas adalah fasilitas pelayanan kesehatan yang menyelenggarakan upaya kesehatan masyarakat dan upaya kesehatan perseorangan tingkat pertama, dengan lebih mengutamakan upaya promotif dan preventif, untuk mencapai derajat kesehatan masyarakat yang setinggitingginya di wilayah kerjanya. Puskesmas sebagai sarana pelayanan kesehatan wajib menyediakan fasilitas guna mencapai derajat kesehatan masyarakat yang setinggi-tingginya.

Peraturan Menteri Kesehatan Republik Indonesia Nomor 269/MENKES/PER/I/2008 Tentang Rekam Medis adalah berkas yang berisi catatan dan dokumen tentang identitas pasien, pemeriksaan, pengobatan, tindakan dan pelayanan lain kepada pasien pada fasilitas pelayanan kesehatan. Filing yang merupakan media untuk penyimpanan, penyedia dan pelindung berkas rekam medis pasien. Oleh karena itu setiap dokumen rekam medis disimpan pada rak penyimpanan, rak penyimpanan bertujuan untuk mencegah kerusakan dan hilangnya berkas rekam medis dan memudahkan pencarian kembali berkas rekam medis apabila sewaktu-waktu dibutuhkan. Ukuran antropometri tenaga kerja akan dapat menjadi dasar untuk membuat suatu desain alat-alat kerja yang sepadan bagi tenaga kerja yang akan menggunakannya. Hal ini bertujuan agar dapat menciptakan kenyamanan, kesehatan, keselamatan, dan estetika kerja. Data antropometri juga akan menentukan bentuk, ukuran dan dimensi yang tepat dan berkaitan dengan produk yang dirancang dan manusia yangakan menggunakan/mengoperasikan produk tersebut (Putri, 2014). 
Ergonomi adalah salah satu cabang ilmu yang sistematis untuk memanfaatkan informasi-informasi mengenai sifat, kemampuan dan keterbatasan manusia merancang suatu sistem kerja, sehingga manusia dapat hidup dan bekerja pada sistem itu dengan baik, yaitu mencapai tujuan yang diinginkan melalui pekerjaan itu dengan efektif, aman, dan nyaman. Fokus dari ergonomi adalah manusia dan interaksinya dengan produk, peralatan, fasilitas, prosedur dan lingkungan pekerja serta kehidupan sehari-hari dimana penekanannya adalah pada faktor manusia (Ngaliman, 2017).

Berdasarkan pengamatan awal yang dilakukan peneliti di Puskesmas Sooko Kabupaten Ponorogo menurut hasil pengamatan jumlah rak yang tersedia saat ini yaitu sebanyak 2 rak penyimpanan dokumen rekam medis. Jenis rak yang digunakan disana 1 rak dari bahan aluminium dengan ukuran lebar 1,20 m dan tinggi $1,70 \mathrm{~m}$ serta 1 rak dari kayu yang tinggi dengan ukuran lebar 2,62 m dan tinggi 2,14 $\mathrm{m}$.

Penyebab rak penyimpanan dokumen rekam medis yang terlalu tinggi dalam kondisi ini memungkinkan terjadinya ergonomi petugas filling sehingga saat petugas mengambil dokumen rekam medis membutuhkan alat bantu. Petugas filling juga mengeluhkan kelelahan, rasa nyeri pada punggung, efek jangka panjang yang akan menyertai berikutnya akibat dari pengambilan berkas rekam medis yang tidak ergonomis, timbulnya rasa nyeri pada bahu dan kaki akibat ketidak sesuaian pekerja dan lingkungan.

Kondisi ini memungkinkan terjadinya ergonomi petugas filling sebab rak yang terlalu tinggi berdampak terhadap kesehatan dan keselamatan petugas filling di Puskesmas Sooko. Tujuan umum dari penelitian ini adalah untuk mengetahui rak penyimpanan dokumen rekam medis terhadap ergonomi petugas filling di Puskesmas Sooko Kabupaten Ponorogo.

\section{METODE PENELITIAN}

Jenis penelitian yang digunakan adalah deskriptif kualitatif. Lokasi penelitian adalah di Puskesmas Sooko
Kabupaten Ponorogo. Sampel penelitian adalah 3 petugas filling dan rak penyimpanan dokumen rekam medis. Hasil pengolahan data penelitian ini dianalisa secara dekriptif.

\section{HASIL PENELITIAN}

Ukuran Rak Penyimpanan Dokumen Rekam Medis di Puskesmas Sooko Kabupaten Ponorogo April 2019

Tabel 1 Rak Penyimpanan dokumen

\begin{tabular}{|c|c|c|}
\hline Keterangan & Komponen & Ukuran \\
\hline \multirow{5}{*}{$\begin{array}{l}\text { Rak } \\
\text { Penyimpanan } \\
\text { DRM } \\
\text { alumunium }\end{array}$} & Tinggi rak & $124 \mathrm{~cm}$ \\
\hline & & \\
\hline & Lebar rak & $262 \mathrm{~cm}$ \\
\hline & $\begin{array}{l}\text { Tinggi sub } \\
\text { rak }\end{array}$ & $42 \mathrm{~cm}$ \\
\hline & $\begin{array}{l}\text { Lebar sub } \\
\text { rak }\end{array}$ & $66 \mathrm{~cm}$ \\
\hline \multirow{4}{*}{$\begin{array}{l}\text { Rak } \\
\text { Penyimpanan } \\
\text { DRM kayu }\end{array}$} & Tinggi rak & $170 \mathrm{~cm}$ \\
\hline & Lebar rak & $120 \mathrm{~cm}$ \\
\hline & $\begin{array}{l}\text { Tinggi sub } \\
\text { rak }\end{array}$ & $43 \mathrm{~cm}$ \\
\hline & $\begin{array}{l}\text { Lebar sub } \\
\text { rak }\end{array}$ & $31 \mathrm{~cm}$ \\
\hline
\end{tabular}


Anthropometri posisi berdiri petugas filling di Puskesmas Sooko Kabupaten Ponorogo April 2019

Tabel 2 Anthropomtri petugas

\begin{tabular}{|c|c|c|c|c|c|c|c|}
\hline No & $\begin{array}{c}\text { Jenis } \\
\begin{array}{c}\text { Anthropom } \\
\text { etri }\end{array} \\
\end{array}$ & $\begin{array}{c}\text { Petugas } \\
\mathbf{1} \\
(\mathbf{c m}) \\
\end{array}$ & $\begin{array}{c}\text { Petugas } \\
\mathbf{2} \\
(\mathbf{c m}) \\
\end{array}$ & $\begin{array}{c}\text { Petugas } \\
\mathbf{3} \\
(\mathbf{c m})\end{array}$ & $\begin{array}{l}\text { Rata- } \\
\text { Rata } \\
\text { (cm) }\end{array}$ & $\begin{array}{c}\text { Percent } \\
\text { il-5 } \\
(\mathrm{cm}) \\
\end{array}$ & $\begin{array}{c}\text { Percentil- } \\
95 \\
(\mathbf{c m}) \\
\end{array}$ \\
\hline 1. & $\begin{array}{l}\text { Tinggi } \\
\text { Badan }\end{array}$ & 152 & 153 & 165 & 156,5 & 146,7 & 166,2 \\
\hline 2. & Tinggi bahu & - & - & - & - & - & - \\
\hline 3. & Tinggi Siku & 33 & 41 & 42 & 38,6 & 32 & 45,1 \\
\hline 4. & $\begin{array}{l}\text { Tinggi } \\
\text { Pinggang }\end{array}$ & 93 & 95 & 92 & 93,3 & 91,2 & 95,3 \\
\hline 5. & $\begin{array}{l}\text { Panjang } \\
\text { Depa }\end{array}$ & 143 & 148 & 150 & 147 & 142,2 & 151,8 \\
\hline 6. & $\begin{array}{l}\text { Panjang } \\
\text { Lengan }\end{array}$ & 66 & 72 & 74 & 70,6 & 65 & 76,1 \\
\hline 7. & $\begin{array}{l}\text { Panjang } \\
\text { Lengan Atas }\end{array}$ & - & - & - & - & - & - \\
\hline 8. & $\begin{array}{l}\text { Panjang } \\
\text { Lengan } \\
\text { Bawah }\end{array}$ & - & - & - & - & - & - \\
\hline 9. & Lebar Bahu & 42 & 50 & 47 & 46,3 & 41 & 51,6 \\
\hline 10. & Lebar Dada & 30 & 28 & 40 & 32,6 & 24 & 41,2 \\
\hline
\end{tabular}

Dari hasil pengukuran anthropometri kemudian dilakukan perhitungan standar deviasi, percentile- $5^{\text {th }}$ dan percentile- $95^{\text {th }}$ untuk mengetahui kesesuaian antara rak penyimpanan dokumen rekam medis dengan anthropometri petugas di filling Puskesmas Sooko Kabupaten Ponorogo. Penghitungan dengan cara menghitung rata-rata setiap pengukuran anthropometri $X=\sum \frac{f x}{N}$, menghitung standar deviasi dengan rumus $\mathrm{SD}=\sqrt{\frac{\sum f \cdot x^{2}}{N}}$, percentile $5^{\text {th }}$ dengan rumus $5^{\text {th }}=X-1,645 . S D$ dan percentile $95^{\text {th }}$ dengan rumus $95^{\text {th }}=$ $\mathrm{X}+1,645 . \mathrm{SD}$ (Wignjosoebroto, 2006).
Hasil perhitungan anthropometri posisi berdiri petugas filling Puskesmas Sooko Kabupaten Ponorogo April 2019

Tabel 3. Jenis Anthropometri posisi berdiri petugas

\begin{tabular}{llc}
\hline \multirow{2}{*}{ No } & $\begin{array}{c}\text { Jenis } \\
\text { Antropometri }\end{array}$ & Nilai (cm) \\
\hline 1 & Tinggi badan & \\
\hline \multirow{3}{*}{} & Standar & 5,9 \\
& Deviasi & 146,7 \\
\cline { 2 - 3 } & Percentil-5 & 166,2 \\
\cline { 2 - 3 } & Percentil-95 & \\
\hline 2 & Tinggi bahu & \\
\hline \multirow{3}{*}{} & Standar & - \\
\cline { 2 - 2 } & Deviasi & - \\
\cline { 2 - 3 } & Percentil-5 & \\
\cline { 2 - 3 } 3 & Percentil-95 & \\
\hline \multirow{3}{*}{} & Tinggi siku & \\
\cline { 2 - 3 } & Standar Deviasi4 & \\
\hline & Percentil-532 & 45,1 \\
\hline
\end{tabular}




\section{Jurnal Delima Harapan 2020}

\begin{tabular}{|c|c|c|}
\hline No & $\begin{array}{l}\text { Jenis } \\
\text { Antropometri }\end{array}$ & Nilai (cm) \\
\hline \multirow[t]{4}{*}{4} & Tinggi pinggang & \\
\hline & $\begin{array}{l}\text { Standar } \\
\text { Deviasi }\end{array}$ & 1,2 \\
\hline & Percentil-5 & 91,2 \\
\hline & Percentil-95 & 95,3 \\
\hline \multirow[t]{4}{*}{5} & Panjang depa & \\
\hline & $\begin{array}{l}\text { Standar } \\
\text { Deviasi }\end{array}$ & 2,9 \\
\hline & Percentil-5 & 142,2 \\
\hline & Percentil-95 & 151,8 \\
\hline \multirow[t]{4}{*}{6} & Panjang lengan & \\
\hline & $\begin{array}{l}\text { Standar } \\
\text { Deviasi }\end{array}$ & 3,3 \\
\hline & Percentil-5 & 65 \\
\hline & Percentil-95 & 76,1 \\
\hline \multirow[t]{4}{*}{7} & Panjang lengan atas & \\
\hline & $\begin{array}{l}\text { Standar } \\
\text { Deviasi }\end{array}$ & - \\
\hline & Percentil-5 & - \\
\hline & Percentil-95 & - \\
\hline \multirow[t]{4}{*}{8} & Panjang lengan bawah & \\
\hline & $\begin{array}{l}\text { Standar } \\
\text { Deviasi }\end{array}$ & - \\
\hline & Percentil-5 & - \\
\hline & Percentil-95 & - \\
\hline \multirow[t]{3}{*}{9} & Lebar bahu & \\
\hline & $\begin{array}{l}\text { Standar } \\
\text { Deviasi }\end{array}$ & 3,2 \\
\hline & Percentil-5 & 41 \\
\hline
\end{tabular}

\begin{tabular}{llc}
\hline & Percentil-95 & 51,6 \\
\hline 10 & Lebar dada & \\
\hline \multirow{3}{*}{} & $\begin{array}{l}\text { Standar } \\
\text { Deviasi }\end{array}$ & 5,2 \\
\cline { 2 - 2 } & Percentil-5 & 24 \\
\cline { 2 - 2 } & Percentil-95 & 41,2 \\
\hline
\end{tabular}

Anthropometri berat badan petugas filling di Puskesmas Sooko Kabupaten Ponorogo April 2019

Tabel 4. Anthropometri berat badan petugas

\begin{tabular}{llccc}
\hline $\begin{array}{l}\text { N } \\
\text { o. }\end{array}$ & $\begin{array}{l}\text { Jenis } \\
\text { Anthropo } \\
\text { metri }\end{array}$ & $\begin{array}{l}\text { Petu } \\
\text { gas 1 }\end{array}$ & $\begin{array}{l}\text { Petu } \\
\text { gas 2 }\end{array}$ & $\begin{array}{l}\text { Petu } \\
\text { gas 3 }\end{array}$ \\
\hline 1. & $\begin{array}{l}\text { Berat } \\
\text { Badan }\end{array}$ & $52 \mathrm{~kg}$ & $50 \mathrm{~kg}$ & $75 \mathrm{~kg}$ \\
\hline
\end{tabular}

Tabel 5. Anthropometri jangkauan tangan ke atas, lebar bahu dan panjang depa petugas filling di Puskesmas Sooko Kabupaten Ponorogo April 2019

\begin{tabular}{ccccccc}
\hline Responden & $\begin{array}{c}\text { Jangkauan } \\
\text { Tangan Ke } \\
\text { Atas }\end{array}$ & $\begin{array}{c}\text { Hasil } \\
\text { Kuadrat }\end{array}$ & $\begin{array}{c}\text { Panjang } \\
\text { Depa }\end{array}$ & $\begin{array}{c}\text { Hasil } \\
\text { Kuadrat }\end{array}$ & $\begin{array}{c}\text { Lebar } \\
\text { Bahu }\end{array}$ & $\begin{array}{c}\text { Hasil } \\
\text { Kuadrat }\end{array}$ \\
\hline 1. & $185 \mathrm{~cm}$ & $34.225 \mathrm{~cm}$ & $143 \mathrm{~cm}$ & $20.449 \mathrm{~cm}$ & $42 \mathrm{~cm}$ & $1.764 \mathrm{~cm}$ \\
2. & $189 \mathrm{~cm}$ & $35.721 \mathrm{~cm}$ & $148 \mathrm{~cm}$ & $21.904 \mathrm{~cm}$ & $50 \mathrm{~cm}$ & $2.500 \mathrm{~cm}$ \\
3. & $202 \mathrm{~cm}$ & $40.804 \mathrm{~cm}$ & $150 \mathrm{~cm}$ & $22.500 \mathrm{~cm}$ & $47 \mathrm{~cm}$ & $2.209 \mathrm{~cm}$ \\
Jumlah & $576 \mathrm{~cm}$ & $110.750 \mathrm{~cm}$ & $441 \mathrm{~cm}$ & $64.853 \mathrm{~cm}$ & $139 \mathrm{~cm}$ & $6.473 \mathrm{~cm}$ \\
\hline
\end{tabular}


Tabel 6.Perbandingan Data Antropometri Untuk Orang Indonesia, Anthropometri Petugas dan Ukuran Rak Penyimpanan Di Puskesmas Sooko Kabupaten Ponorogo April 2019

\begin{tabular}{c|l|ccc}
\hline No. & \multicolumn{1}{c}{ Kriteria } & \multicolumn{1}{c}{$\begin{array}{c}\text { Rata-Rata } \\
\text { Anthropometri } \\
\text { Orang } \\
\text { Indonesia }\end{array}$} & $\begin{array}{c}\text { Anthropometri } \\
\text { Petugas }\end{array}$ & $\begin{array}{c}\text { Ukuran Rak } \\
\text { Penyimpanan }\end{array}$ \\
\hline $\mathbf{1 .}$ & $\begin{array}{l}\text { Tinggi jangkauan ke } \\
\text { atas (diukur dari luar } \\
\text { ujung jari tengah } \\
\text { sampai dengan alas } \\
\text { kaki dalam keadaan } \\
\text { berdiri) }\end{array}$ & $2,02 \mathrm{~m}$ & $1,8 \mathrm{~m}$ & $2,14 \mathrm{~m}$ \\
\hline $\mathbf{2 .}$ & $\begin{array}{l}\text { Panjang depa (diukur } \\
\text { dari ujung jari tengah } \\
\text { kiri sampai dengan } \\
\text { ujung jari tengah } \\
\text { kanan) }\end{array}$ & $1,65 \mathrm{~m}$ & $1,4 \mathrm{~m}$ & $2,62 \mathrm{~m}$ \\
\hline $\mathbf{3 .}$ & $\begin{array}{l}\text { Lebar bahu (diukur } \\
\text { dari bagian luar bahu } \\
\text { kiri sampai ke bagian } \\
\text { luar bahu kanan) }\end{array}$ & $39,8 \mathrm{~cm}$ & $41 \mathrm{~cm}$ & - \\
\hline
\end{tabular}

Tabel 7. Kesesuaian Ukuran Rak Penyimpanan Dokumen Rekam Medis dengan Anthropometri Petugas Filling di Puskesmas Sooko Kabupaten Ponorogo April 2019

\begin{tabular}{|c|c|c|c|c|}
\hline No & $\begin{array}{c}\text { Dimensi } \\
\text { Rak } \\
\text { Penyimpanan } \\
\text { Dokumen } \\
\text { Rekam Medis }\end{array}$ & $\begin{array}{l}\text { Anthropometri } \\
\text { Petugas }\end{array}$ & $\begin{array}{c}\text { Standar } \\
\text { Desain Rak } \\
\text { Penyimpanan }\end{array}$ & $\begin{array}{l}\text { Penilaian } \\
\text { Kesesuaian }\end{array}$ \\
\hline 1. & $\begin{array}{l}\text { Tinggi Rak } \\
(214 \mathrm{~cm} \\
2,14 \mathrm{~m})\end{array}$ & $\begin{array}{l}\text { Jangkauan Tangan } \\
\text { Ke Atas } \\
(180 \mathrm{~cm}=1,8 \mathrm{~m})\end{array}$ & $\begin{array}{l}\text { Tinggi rak > } \\
\text { panjang } \\
\text { jangkauan } \\
\text { tangan ke atas } \\
(214>180)\end{array}$ & $\begin{array}{lr}\text { Belum } & \text { sesuai } \\
\text { karena tinggi rak } \\
\text { lebih tinggi } \\
\text { daripada jangkauan } \\
\text { tangan ke atas }\end{array}$ \\
\hline 2. & $\begin{array}{l}\text { Panjang rak } \\
(262 \mathrm{~cm}= \\
2,62 \mathrm{~m})\end{array}$ & $\begin{array}{l}\text { Panjang depa } \\
\mathrm{cm}=1,4 \mathrm{~m})\end{array}$ & $\begin{array}{l}\text { Panjang rak > } \\
\text { panjang depa } \\
(262>140)\end{array}$ & $\begin{array}{lr}\text { Belum } & \text { sesuai } \\
\text { karena panjang rak } \\
\text { lebih } & \text { panjang } \\
\text { daripada } & \text { panjang } \\
\text { depa } & \end{array}$ \\
\hline
\end{tabular}




\section{PEMBAHASAN}

\section{Rak Penyimpanan Dokumen Rekam Medis di Puskesmas Sooko Kabupaten Ponorogo \\ Rak penyimpanan dokumen} rekam medis di Puskesmas Sooko Kabupaten Ponorogo ada 2. Jenis rak 1 rak dari bahan alumunium dan 1 rak dari kayu. Ukuran rak penyimpanan dokumen rekam medis di Puskesmas Sooko tinggi $214 \mathrm{~cm}$ dan panjang 262 $\mathrm{cm}$. Ukuran rak yang ada belum sesuai dengan anthropometri petugas sehingga ketika bekerja petugas mengalami keluhan dan kelelahan.

Jika landasan kerja terlalu rendah, tulang belakang akan membungkuk ke depan dan jika terlalu tinggi bahu akan terangkat dari posisi rileks, sehingga menyebabkan bahu dan leher menjadi tidak nyaman (Sandres dan Mc Cormick, 1987 dalam Tarwaka,dkk,2004).

Kesesuaian ukuran rak penyimpanan dokumen rekam medis dengan anthropometri petugas, agar petugas dapat menjalankan pekerjaannya dengan baik maka tinggi rak disesuaikan dengan rata-rata panjang jangkauan tangan ke atas petugas, panjang rak disesuaikan dengan panjang depa petugas. Sehingga untuk mengurangi kelelahan petugas dalam bekerja sebaiknya disesuaikan antara ukuran rak penyimpanan dokumen rekam medis dengan anthropometri petugas. Jadi, jika ukuran rak penyimpanan dokumen rekam medis dengan anthropometri sudah sesuai petugas dalam melaksanakan tugasnya mendapatkan kenyamanan dalam kerja serta K3 terjamin dengan baik, juga dapat meningkatkan produktifitas kerja.

Kesesuaian antara Rak Penyimpanan Dokumen Rekam Medis dengan Anthropometri Petugas Filling di Puskesmas Sooko Kabupaten Ponorogo
Tinggi Rak Penyimpanan Dokumen Rekam Medis

Standar ukuran tinggi rak penyimpanan dokumen rekam medis yaitu dari hasil pengukuran jangkauan tangan ke atas hasil percentil-5 yaitu 180 $\mathrm{cm}$. Standar ukuran tinggi rak penyimpanan dokumen rekam medis yaitu ukuran panjang jangkauan tangan ke atas percentil-5. Dari pengukuran tinggi rak penyimpanan dokumen rekam medis di Puskesmas Sooko Kabupaten Ponorogo diperoleh $214 \mathrm{~cm}$ menunjukkan bahwa tinggi rak yang ada belum sesuai dengan standar.

Rancangan fasilitas kerja untuk lokasi jarak jangkauan terpendek dengan percentil-5 dan lokasi jarak jangkauan panjang menggunkan data terbesar percentil-95 (Sritomo, 2006).

Rak penyimpanan dokumen rekam medis yang terlalu tinggi membuat petugas filling di Puskesmas Sooko Kabupaten Ponorogo kesulitan untuk menjangkau, mengambil, dan mengembalikan dokumen rekam medis, sehingga ukuran tinggi rak bisa disesuaikan dengan standar yang telah dihitung.

\section{Panjang Rak Penyimpanan Dokumen Rekam Medis \\ Standar ukuran panjang rak} penyimpanan dokumen rekam medis yaitu dari hasil pengukuran panjang depa hasil percentil-5 yaitu $140 \mathrm{~cm}$. Standar ukuran panjang rak penyimpanan dokumen rekam medis yaitu ukuran panjang depa percentil-5. Dari pengukuran panjang rak penyimpanan dokumen rekam medis di Puskesmas Sooko Kabupaten Ponorogo diperoleh $262 \mathrm{~cm}$ menunjukkan bahwa panjang rak yang ada belum sesuai dengan standar.

Rancangan fasilitas kerja untuk lokasi jarak jangkauan terpendek dengan percentil-5 dan lokasi jarak jangkauan panjang menggunakan data terbesar percentil-95 (Sritomo, 2006). 
Rak penyimpanan dokumen rekam medis yang terlalu panjang membuat petugas filling di Puskesmas Sooko Kabupaten Ponorogo kesulitan untuk menata, mengambil, dan mengembalikan dokumen rekam medis, sehingga ukuran panjang rak bisa disesuaikan dengan standar yang telah dihitung.

\section{Anthropometri Posisi Berdiri Petugas Filling Puskesmas Sooko Kabupaten Ponorogo}

Ukuran anthropometri petugas yang paling kecil diantaranya yaitu tinggi badan $153 \mathrm{~cm}$, tinggi siku petugas filling dengan hasil $33 \mathrm{~cm}$, tinggi pinggang petugas filling dengan hasil $93 \mathrm{~cm}$, panjang depa petugas filling dengan hasil $145 \mathrm{~cm}$, panjang lengan petugas filling dengan hasil $66 \mathrm{~cm}$, lebar bahu petugas filling dengan hasil $42 \mathrm{~cm}$, dan lebar dada petugas filling dengan hasil $30 \mathrm{~cm}$.

Ukuran anthropometri petugas paling besar diantaranya yaitu Ukuran anthropometri petugas yang paling besar diantaranya yaitu tinggi badan petugas filling dengan hasil $165 \mathrm{~cm}$, tinggi siku petugas filling dengan hasil $42 \mathrm{~cm}$, tinggi pinggang petugas filling dengan hasil $95 \mathrm{~cm}$, panjang depa petugas filling dengan hasil $150 \mathrm{~cm}$, panjang lengan petugas filling dengan hasil $74 \mathrm{~cm}$, lebar bahu petugas filling dengan hasil $50 \mathrm{~cm}$, dan lebar dada petugas filling dengan hasil $40 \mathrm{~cm}$.

Dengan mengetahui ukuran anthropometri tenaga kerja dapat dibuat suatu desain alat kerja yang sepadan untuk digunakan oleh tenaga kerja dengan harapan dapat menciptakan kenyamana, kesehatan, keselamatan dan estetika kerja (Sutarman, 1972 dalam Tarwaka,dkk,2004).

Mendesain produk harus disesuaikan dengan ukuran terbesar tubuh yaitu $95^{\text {th }}$ percentile dan ukuran terkecil tubuh yaitu $5^{\text {th }}$ percentile (Santoso,2013).
Anthropometri setiap petugas filling memiliki ukuran yang berbeda, sehingga diperlukan penyesuaian antara anthropometri petugas dengan sarana kerja yaitu rak penyimpanan dokumen rekam medis Puskesmas Sooko Kabupaten Ponorogo. Hasil pengukuran anthropometri petugas filling di Puskesmas Sooko Kabupaten Ponorogo akan digunakan untuk menentukan kesesuaian ukuran rak penyimpanan dokumen rekam medis di Puskesmas Sooko Kabupaten Ponorogo.

\section{KESIMPULAN}

Rak penyimpanan dokumen rekam medis di Puskesmas Sooko Kabupaten Ponorogo ada 2. Jenis rak 1 rak dari bahan alumunium dan 1 rak dari kayu. Rak penyimpanan dokumen rekam medis di Puskesmas Sooko Kabupaten Ponorogo teridentifikasi berukuran tinggi $214 \mathrm{~cm}$ dan panjang $264 \mathrm{~cm}$ belum sesuai dengan anthropometri petugas filling.

Rak penyimpanan dokumen rekam medis terhadap ergonomi petugas filling di Puskesmas Sooko Kabupaten Ponorogo teridentifikasi belum sesuai dengan anthropometri petugas. Standar rak penyimpanan dokumen rekam medis sesuai anthropometri petugas berukuran tinggi $180 \mathrm{~cm}$ dan panjang $140 \mathrm{~cm}$.

Saran yang bisa dilakukan di Puskesmas Sooko Kabupaten Ponorogo yaitu menambahkan alat bantu yang aman sesuai dengan ketentuan K3 untuk melakukan pekerjaan seperti tangga yang aman untuk mengambil dan mengembalikan dokumen rekam medis pasien ataupun alat lain yang dibuat seperti undak-undakan sesuai dengan ketentuan K3.

Penyesuaian rekrutmen petugas baru jika nanti sudah saatnya perekrutan harus dipertimbangkan untuk ukuran tinggi badan, berat badan dan sebagainya. 
DAFTAR PUSTAKA

Ngaliman, Billy, 2016. Ergonomi Dasar-Dasar Studi Waktu \& Gerakan untuk Analisis \& Perbaikan Sistem Kerja. Yogyakarta : C.V ANDI OFFSET.

Peraturan Menteri Kesehatan Republik Indonesia Nomor 269/MENKES/PER/I/2008

Tentang Rekam Medis

Peraturan Menteri Kesehatan Republik Indonesia Nomor 75 Tahun 2014 Tentang Pusat Kesehatan Masyarakat

Rahmawati, dkk. 2017. Perhitungan Kebutuhan Rak Penyimpanan Rekam Medis Pasien Di RS Panti Nugroho, KTI, STIKES Jendral Ahmad Yani, Yogyakarta.

Ramadhan, Mahrizal. 2017. Menghitung Kebutuhan Rak Penyimpanan Berkas Rekam Medis Pasien Berdasarkan Aspek Antropometri Petugas Rekam Medis Di RSUD Kota Yogyakarta. KTI, Universitas Muhammadiyah Surakarta, Surakarta.

Rustiyanto, Ery, 2011. Manajemen Filling Dokumen Rekam Medis dan Informasi Kesehatan. Yogyakarta : Politeknik Kesehatan Pertama Indonesia.

Sugiyono. 2016. Metode Penelitian Kuantitatif, Kualitatif dan $R \& D$. Bandung: PT Alfabet.

Tarwaka, dkk. 2004. Ergonomi Untuk Keselamatan, Kesehatan Kerja dan Produktivitas. Surakarta: Uniba Press.

Uli1, Hilyatin. 2013. Tinjauan Kesehatan dan Keselamat Kerja Di Bagian Filling KTI, Universitas Dian Nuswantoro, Semarang.
Wignjosoebroto, Sritomo. 2006. Ergonomi Studi Gerak dan Waktu. Surabaya: Prima Printing. 